\title{
Digital business transformation: Trends, innovative models, a development program
}

\author{
Tetiana Bochulia $^{1 *}$ \\ ${ }^{1}$ The London Academy of Science and Business, 120 Baker Street, London, W1U 6TU, United \\ Kingdom
}

\begin{abstract}
The article is devoted to solving the current issues on current trends in digital transformation of business as an innovative paradigm due to the development of a multimedia society and the new economy. The essence and the process of forming a digital culture are considered that allowed determining the quantitative and qualitative parameters of its model in accordance with the specifics of the activity and the chosen strategy of the company's development. The process of forming an innovative model of enterprise development on the basis of digital transformation is characterized. The stages of forming an enterprise management policy in the context of innovative development are described. Innovative models of digital development are characterized, according to which the possibility to objectively assess factors and conditions of the organization of digital transformation selecting the necessary direction of development becomes available. The "critical" components of the innovative strategy of increasing the organizational stability of the company are identified. The paper proposes a methodological approach to implementing the transformation program that is accompanied by the development of a digital business model with a step-by-step transition to an innovative basis of activity and adaptation to the digital environment of the business ecosystem.
\end{abstract}

\section{Introduction}

Modern business is moving in the direction of digital transformations from developing road maps and pilot projects to forming an innovative environment, which is characterized by a new paradigm of activity with appropriate methodological transformation. The defining aspect of digital transformation is the change of thinking stereotypes, methods of work and enterprise management, accompanied by the development of a strategy focused on digital solutions of business development [1].

The basis of digital transformation is not so much in implementing innovative technologies, but in a set of changes aimed at developing a new business model with the introduction of digital culture and the formation of integrated professional competencies. The idea of rethinking the ways and tools of doing business with conceptual transformations is

* The corresponding author: t.bochulia@gmail.com 
embedded in a radical change in the business model of the company, corresponding to the changes inherent in the external business ecosystem [2].

The business model is the company value that determines its pace of development and is an element of the organizational code, the elements of which form a complex system with complex relations, which is the basis of the development model with the transformation of source resources into competitive advantage. Values, as a factor of change, standard of activity and development priority, are an element of the company's culture, which today should correspond to the logic of digital transformations. It is from cultural transformation that the innovative process of a company's digital development should begin, as the culture of activity is a program that includes a knowledge base, reaction models and situational solutions, which together form a roadmap for development.

The task of digital business transformation is becoming more relevant and is considered in the works of various scientists who have their own stance on the digital concept of economics, methods of digital culture, principles of digital transformation of business processes and procedures of organizing the digital economic environment. In particular, leading modern scientists [1-12] have identified an innovative stage in the modern business development with a proposal for a digital concept for the economy. However, less attention is paid to digital innovations of business transformation with the priority of innovative strategy to increase the organizational stability of the company. This issue is currently less studied by scientists and is considered primarily from the standpoint of the use of digital technologies, which is not fully consistent with the context of the global digital environment. This encourages intensification of research of a new nature to determine not only the essence of digital transformation, but also to propose a specific action program for implementing the transformation program with the development of a digital business model with a step-by-step transition to innovation [13-78].

\section{Research Analysis and Goal-Setting}

The purpose of this research is to develop a program of digital business transformation with the definition of mandatory components of the innovative strategy to increase the organizational stability of the company.

The totality of general scientific methods of knowledge processes and phenomena that take place in the modern economy under the influence of digital technologies has become theoretical and methodological basis of scientific research, which applied: a gnoseological method for concretization the essence and components of digital culture; a system-structural method for specifying the provisions of data management in the digital culture system; a method of analogy for forming an innovative model of enterprise development based on digital transformation; methods of theoretical generalization and comparison to determine the prospects and directions of digital business transformation with the outline of criteria for innovative strategies to increase the organizational stability of the company.

\section{Research Results}

There is no universal template for shaping the digital culture: it should be developed in accordance with the company's mission, the context of the organizational environment and the model of digital partnership, which includes the development of professional competencies. However, for the digital culture buildup it is necessary to be guided by the defining components that are the basis for designing its individual model. 
1. An advisory nature of management. Establishing a horizontal hierarchy of decisionmaking that provides for the expansion of powers at all levels of government and is a transition to a new organizational level, taking into account the guidelines of management.

2. An external accent. The priority of establishing a partnership with a focus on mutual satisfaction of the interests of the company and the external business ecosystem and updating the professional knowledge base.

3. A risk profile. Forming the models of reaction to risks inherent in the company's business environment and external business ecosystem. Defining a group of acceptable solutions that is constantly updated in accordance with the pace and directions of development.

4. A focus of active actions. The operational nature of decision-making with a focus on short-term plans, which are systemic elements of the overall strategy of the company. This allows constant demonstration of a clear result, which is an effective motivational tool for development.

5. An effective partnership. Establishing an effective system of interaction and cooperation with the exchange of information, knowledge, competencies, which is realized in forming a collaborative environment united by a single goal of development.

Each of the described components of the model differs in quantitative and qualitative parameters in accordance with the specifics of the activity and the chosen development strategy of the company. The development of corporate culture is carried out at the stages of essential streamlining, initiation of transformations and streamlining of processes to implement a new organizational model.

The most responsible is the stage of essential ordering, because it determines the target characteristics of digital culture in accordance with the mission of the activity and strategies for the company development, which is further formalized in a program of specific actions, which, after coordination, is a code of current and targeted professional conduct regarding the implementation of the purpose of the activity.

Transformations are initiated on the basis of the fundamental provisions given in the code of conduct providing for creation of the autonomous mode of the changes effective in the aspect of the defined development goal. At this stage, the company's value system is updated, which should be the same for the entire team of professionals. There should also be provided the formation of temporary teams to perform specialized tasks, which is more efficient in terms of resource and time. Specialists are grouped into work teams according to the principles set out in the Code of Digital Culture, which should be the same for each of the specialists. This allows modelling professional teams with minimal risk of unproductiveness and a high level of efficiency execution of a defined task.

Streamlining of the processes to implement the new organizational model involves making changes to the existing model with its refinement to the reference, namely defined in the development roadmap. At this stage, it is necessary to constantly evaluate the results obtained and monitor deviations from the expected indicators. The basic provisions of information management that is an important point of the digital culture code should be taken into account.

1. Data culture. Expansion of the system of analytical applications and tools, which provides for the establishment of operational access of each of the company's specialists to the database. The use of integrated analytical skills allows enhancing the efficiency of decision-making, as it is based on the integrated competencies of specialists in various fields of qualification and knowledge.

2. Adapted technologies. The software and hardware complex of the enterprise should be convenient for use not only by specialists with technological competencies, and also by each of the employees who operate with data for making operational and strategic decisions. This 
allows expanding the formulation of hypotheses and developing activity scenarios with their adjustment in accordance with the constant monitoring of data.

3. Information experimentation. Digital culture provides motivation to experiment with data on their interpretation in accordance with the strategy and variable values of processes that adjust the database, and therefore affect the reaction models and solution hypotheses.

4. Binarity of the information management. Information management should be a twoway process in terms of horizontal and vertical hierarchies, which corresponds to the concept of digital culture.

5. An emphasis on objectivity. Reinforcement of decisions with extended information that allows reducing the subjectivity of decisions and increasing their quality parameters for the task.

The modern philosophy of business is to create an innovative environment with a developed service of digital transformations, which allows modifying business processes and implementing a new organizational model. Underlying these changes is digital culture as a tool for implementing a systematic approach to shaping business values, which consists in the integration of information management, innovative models and extended competencies (Fig. 1).



Fig. 1. The formation of an innovative model of an enterprise development on the basis of digital transformation (developed on the basis of [2-4]).

A business process system of company's innovation should be focused on solutions that gradually (with step-by-step changes) transform the traditional model of activity, which is a manifestation of a compromise (or moderate) strategy.

In the perspective of digital innovations, the companies' activity acquires a new status, form and essence, which influences traditional management decisions and determines the developed basic provisions, according to which there is a formation of a new system of values as the main factor of business development (Fig. 2).

For business, the basic formula of effective management consists of elements of planning, active processes, control and advisory actions, updated processes. This is the necessary quantum of management, which regulates the effectiveness of decisions as a result of processing structured and unstructured information. This formula is the basis for framing the 
company's management policy, which makes the context of development in accordance with the mission (Table 1).

Traditional factors

Innovative factors

Processes and tools

Structured information

Factors, conditions of activity

Management patterns

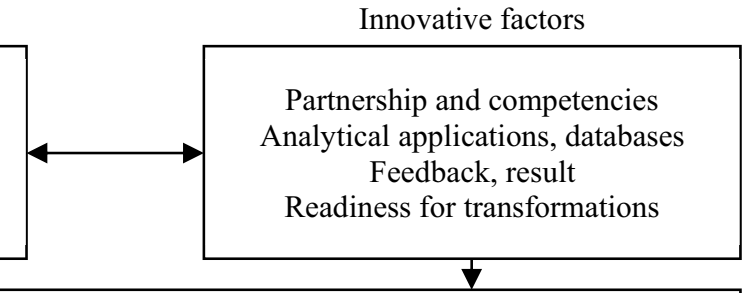

Formation of team structure of activity (combination of different functional experience and professional competencies, goal, extended motivational tools)

Building an organizational system of tribes (acceleration of creative innovations, adaptation of the system to changes, flexibility of decisions and reality of the result)

Expansion of information channels (branching of communication links, constancy of strategic sessions, focus on information partnership)

Simplifying the transition from idea to result
Expansion of qualitative parameters of the organizational model
Increasing productivity activities
Strengthening partnerships and interaction

Fig. 2. The systemic nature of business in the context of digital transformations (developed on the basis of [5-6]).

Table 1. The enterprise management policy in the context of innovative development.

\begin{tabular}{|l|l|}
\hline \multicolumn{1}{|c|}{ Stages } & \multicolumn{1}{c|}{ Characterization } \\
\hline $\begin{array}{l}\text { Business ecosystem } \\
\text { analysis }\end{array}$ & $\begin{array}{l}\text { Study of the factors of internal and external ecosystem for their impact on } \\
\text { the company's activities with the definition of the principles that determine } \\
\text { the parameters of integration of management tools with the business model }\end{array}$ \\
\hline $\begin{array}{l}\text { Formulating a } \\
\text { mission and } \\
\text { development } \\
\text { strategy }\end{array}$ & $\begin{array}{l}\text { Application of a systematic approach to the organization of activities } \\
\text { taking into account the capabilities of management and information } \\
\text { technology with the support of the integration of professional competencies } \\
\text { and the initiative of transformations relevant to the external business } \\
\text { environment }\end{array}$ \\
\hline $\begin{array}{l}\text { Evaluating activity } \\
\text { parameters }\end{array}$ & $\begin{array}{l}\text { Identification of core competencies that meet the development strategy and } \\
\text { allow responding quickly to the need for change and transformation. An } \\
\text { indicator of the effectiveness of the program of activities is the result that } \\
\text { can be achieved through the introduction of innovative managerial } \\
\text { technologies }\end{array}$ \\
\hline $\begin{array}{l}\text { Designing a pilot } \\
\text { development } \\
\text { program }\end{array}$ & $\begin{array}{l}\text { Emphasis on current tasks of activity with transition to transformations } \\
\text { corresponding to realities of time and conditions of activity in external } \\
\text { business ecosystem. The development program is constantly being } \\
\text { finalized, forming a road map with the possibility of timely adjustments }\end{array}$ \\
\hline $\begin{array}{l}\text { Forming an } \\
\text { advisory and } \\
\text { consultative system }\end{array}$ & $\begin{array}{l}\text { Organization of a management subsystem responsible for providing } \\
\text { recommendations and monitoring the effectiveness of decisions, adjusting } \\
\text { the current and strategic objectives of the activity on the basis of relevant } \\
\text { structured and unstructured information }\end{array}$ \\
\hline
\end{tabular}


The described management policy (see Table 1) is a universal tool for sustainable development, as it takes into account different areas of activity in accordance with the specified external parameters of the business. Accordingly, the business model is being updated to take into account changes in approaches to personnel management, transformation of the organizational structure and improvement of the information infrastructure, which collectively identifies innovative digital ways of effective partnership. Digital development is characterized by three key models, each of which outlines a set of necessary business transformations (Fig. 3).

At the stage of decision-making on designing a digital business model it is necessary to determine the main provisions of the conceptual scheme, according to which it is possible to objectively assess the factors and conditions of digital transformation with the choice of the desired direction of development.



Fig. 3. Innovative models of digital development (developed on the basis of [7-9]).

Digital development is conceptually based on devising a new value business proposal that transforms the experience of expanding the hypothesis and development strategy, not limited to achieving one goal, but contributing to a multi-objective strategy with their gradual achievement according to the defined priorities for the current time.

It is important for the company to diversify the business with the development of a new idea of activity based on digital technologies, namely the developed mobile, social, cloud, analytical and communication technologies that expand business opportunities in information processes to ensure balanced development.

Starting the digital transformation, the company is developing a fundamentally new business model, which covers two areas of activity: a systemic nature and analyticity. The first involves the transition to a new type of information management, based on the postulate that business is a comprehensive system with complex relationships that describe management models at each stage of decision-making. Analyticity is associated with the expansion of qualitative and quantitative data parameters that form the basis of the information infrastructure of the enterprise. Accordingly, system and analytical processes form the basis of a new business model, which is characterized by variability in the operation of information in accordance with the task and the general development hypothesis (Fig. 4).

Enterprises that have decided to start a project of global innovation transformations carry out reorganization according to the model selected (see Fig. 4) or make decisions of complex transformation with transition between new business models according to the defined development strategy. 
This choice is determined by the real state of the company that covers such categories as behaviour, external environment, the process of managerial thinking, limiting and motivational beliefs, and values.



Defining a new position in the external business system by developing an innovative proposal based on digital technologies

Efficiency in adapting to changes in conditions and factors of external environment with the flexibility of the management system

A complex, multi-level system of information relations in the business ecosystem

A value aspect in forming a partnership with the establishment of a common goal and equal rights and responsibilities

Fig. 4. The methodical aspect of devising new business models.

According to the combination of these categories, the basis of the future model is characterized that determines the new organizational code for the company for the period of implementation of the chosen development strategy. The chosen model should provide the basis for organizational stability of the company with an emphasis on the efficiency of business processes and efficiency of activity. Organizational stability is achieved through the productive use of basic resources, namely time, information, staff, assets and core competencies of the enterprise.

To increase organizational stability, the company can choose one of the strategies, each of which is based on a certain «critical» component that is the core in overcoming the limiting factors, the formation of models of reactions and implementation of innovations (Table 2).

Innovative business development is possible based on the use of «critical» components of the strategy (see Table 2), which can be combined in accordance with the priority task for a certain period of time. Such «critical» components are factors in the development of organizational stability, in the qualitative parameters of which the potential for further transformations is laid, which is expressed in the formulation of the mission determining the purpose and meaning of activities, is a guide for business processes with adjustment of development vectors. The mission is a reference point for business and the foundation of activity, on the basis of which there is built the system of corporate values, which are factors of the company's progress and its organizational principles.

Each company individually chooses the values that are core to the activity, but there are core values (respect for people, quality service, excellence), which are the guiding principles on which the company forms its response models, develops strategy and determines the direction of transformation [10]. The choice of values begins with the definition of the mission of the activity, on the basis of which the future prospects and ways to achieve them are outlined. The mission allows not only starting and ending the transformation program, but also laying the foundation for balanced and sustainable development. Implementation of 
the program of transformations provides orientation on the approach with step-by-step implementation of transformations.

Table 2. Innovative strategies to increase the organizational stability of the company.

\begin{tabular}{|c|l|}
\hline $\begin{array}{c}\text { The «critical» } \\
\text { component of the } \\
\text { strategy }\end{array}$ & \multicolumn{1}{c|}{ Characterization } \\
\hline Professional coaching & $\begin{array}{l}\text { Organizing a professional growth environment by supporting change } \\
\text { initiatives and expanding motivational tools of both tangible and } \\
\text { intangible nature. The priority task is to maintain the working condition } \\
\text { of staff and focus on expanding their integrated professional } \\
\text { competencies }\end{array}$ \\
\hline Leadership scenarios & $\begin{array}{l}\text { The priority of innovative goals with modelling business processes } \\
\text { with the future perspective of development, changing managerial } \\
\text { thinking and focusing on the courage to change and transformational } \\
\text { processes. A complex nature of innovation implementation with the } \\
\text { encouragement of new ideas and expansion of partnership }\end{array}$ \\
\hline Intensive development & $\begin{array}{l}\text { To maintain and increase organizational stability, it is necessary to } \\
\text { ensure the continuity of staff training with the development of } \\
\text { professional competencies of an interdisciplinary nature that consists in } \\
\text { expanding knowledge and skills to perform various tasks and work in } \\
\text { various cross-functional teams }\end{array}$ \\
\hline A partnership incentive & $\begin{array}{l}\text { The organization of the company's work on the basis of the formation } \\
\text { of tribes: associations of cross-functional teams with the promotion of } \\
\text { professional partnerships as one of the factors of effective business. } \\
\text { Transition to corporate reorganization with the priority of digital } \\
\text { culture }\end{array}$ \\
\hline
\end{tabular}

1. Defining the goal and outlining the desired results. Planning in the program of transformations of core competencies that companies need to adapt to the current conditions of the external business ecosystem and achieve organizational stability. This is a rejection of the traditional improvement of key activity indicators in favour of definition of new target indicators of activity improvement. At this stage, it is envisaged not only to achieve shortterm goals, but also to analyse trends in the development of the internal and external environment with a focus on innovation.

2. Outlining the necessary changes and transformations. Reforming activities on the basis of the program of delegating authority to decision-making, i.e., increasing initiative in the management and development of innovative projects.

3. Expanding the scale of change. Adjustment of the program of transformations with orientation on the development of models of reactions, ability to operatively adapt to external factors of business ecosystem with definition of concrete actions for realization of each of points of the program of changes.

4. Future target landmarks of transformations. Expansion of the set of target landmarks in accordance with monitoring changes in the external environment and the adjustment of the overall management system to the new development strategy.

5. Monitoring of resources and opportunities. Determining the qualitative parameters of internal relationships at the level of the operating model, strategy and management system in general that allows forming a real idea of the resource state. Defining targets for transformations is accompanied by identifying key elements of transformations:

- objectivity - reliability and factual justification of target indicators and direction of activity;

- a system of core competencies - determination of the actual and necessary level of core competencies for the program of transformations and development of activity; 
- a corporate culture analysis - a purposeful analysis of the features of corporate culture, on the basis of which an increase in the level of organizational stability is achieved;

- an analysis of personalized benefits - analysis of available opportunities to identify and implement a large-scale program of transformations. This is an expansion of the range of factors that are analysed to increase sensitivity in assessing the prospects and realities of achieving the goal.

The program of transformations should include innovations, the implementation of which should meet certain values of the company, and therefore be part of the overall mission, which is part of one of the available hypotheses of development. To effectively transform a company's business, it is necessary to be willing to compromise on risks, be flexible in responding to changes in the business ecosystem and adhere to the investment philosophy [11].

Digital transformations are based on understanding the governing apparatus of essence and the nature of changes and readiness for such transformations, which is accordingly implemented in a set of tasks that collectively serve a single purpose - development that corresponds to the reality of the digital stage without managerial asymmetry (Table 3) [12].

Table 3. Purpose parameters of digital business transformation.

\begin{tabular}{|c|l|}
\hline Parameter & \multicolumn{1}{c|}{ Characteristic } \\
\hline Control & $\begin{array}{l}\text { A discipline of decisions in each management subsystem. Willingness to delegate } \\
\text { control with structuring of the reporting system among the subjects of leadership } \\
\text { influence. Horizontal hierarchy in information provision of control }\end{array}$ \\
\hline Initiative & $\begin{array}{l}\text { Understanding the extent of the real need for digital initiatives with basic decision } \\
\text { making and inherent risks. Following the chosen goal without moving on to other } \\
\text { projects. Application of a cascade strategy in decisions and processes, which } \\
\text { minimizes the risk of project depreciation due to incompleteness of previous tasks. } \\
\text { Ability to determine in a timely manner the prospect of each task for the } \\
\text { productivity of the end result }\end{array}$ \\
\hline Innovation & $\begin{array}{l}\text { Prevalence of new forms and methods of business, implementation of creative } \\
\text { approach in the period of enterprise development without levelling off previous } \\
\text { effective models, principles, methods and procedures. Achieving the balance } \\
\text { between new developments and the traditional business model }\end{array}$ \\
\hline Financial \\
provision & $\begin{array}{l}\text { Highlighting a financial goal as a necessary component of sustainable growth. } \\
\text { Focusing on gradual financial provision without income asymmetry, which implies } \\
\text { digital changes with income adjustments without a long-term break in time }\end{array}$ \\
\hline
\end{tabular}

Digital business transformations should be accompanied by the development of a digital business model with a step-by-step transition to an innovative basis of activity and adaptation to the digital environment of the business ecosystem.

The key aspects of digital business transformation.

1. Evaluation of risks and threats. At the stage of decision-making on the digital transformation of business, it is necessary to determine the share of activity income, which may be at risk due to the introduction of digital innovation and the rejection of pre-developed business model. Based on the evaluation results, a pilot version of the model is developed, according to which its effectiveness in ensuring the digital transformation of business is evaluated.

2. Digital skills acquisition. Carrying out global transformations in staff training and updating the software and hardware to facilitate the acquisition of the digital skills that are 
needed to carry out digital transformation of a business and ensuring its further digital development.

3. Determining the most optimal version of a new model. Estimating parameters of the types of digital business models with the subsequent selection of one of them which will be the most effective from the point of view of balance of threats and prospects from the implementation of digital transformations. The company can make a decision or use a readymade model, or develop a new version based on one of the classic digital business models.

4. Defining the source of digital competence. Every business has certain core competencies that ensure the operation and development of the business. According to the adopted project of digital transformations the search for sources of achieving digital advantage, namely, resources that provide efficiency of transition to digital technologies is carried out.

5. Evaluating readiness for digital partnership. The digital partnership ensures greater openness and expanded access to structured and unstructured information that changes the traditional model of interaction at the level of internal and external environment. A company needs to assess its readiness to develop a digital partnership with the transition to construction of new information links.

6. Ensuring the development of digital culture. Ensuring digital transformation through the development of digital culture and its implementation at all levels of the management system with an explanation of its provisions for the staff of the enterprise at all levels of the management hierarchy.

For companies, digital transformation is seen as a new business vision, an innovative way and a new philosophy of activity that collectively determines the meaning of business under modern conditions. Digital transformation is a time-consuming process that involves constant adjustments to the original program of digital change, guided by their key aspects. Adhering to these key aspects, adjusting the program of transformations and carrying out measures for the development of organizational stability, the company achieves stability in the chosen vector of digital transformation, which is defined as a fundamentally new area of activity.

Summarizing the results of the study on the organization of digital business transformation, we propose a method of digital development, which differs in the possibility of application for projects of different scales and focus on systems thinking and innovation (Table 4).

Table 4. A method of providing digital business transformation.

\begin{tabular}{|c|c|}
\hline Basic steps & Characterization \\
\hline $\begin{array}{l}\text { Statement of a } \\
\text { specific task }\end{array}$ & $\begin{array}{l}\text { Formulating the task based on the end result, not intermediate actions. The } \\
\text { task should be specific in accordance with the reality to achieve it some time. } \\
\text { The task should be fully consistent with the values and mission of the activity. } \\
\text { The problem is considered in a broad perspective with the assessment of } \\
\text { alternatives to digital development hypotheses }\end{array}$ \\
\hline $\begin{array}{c}\text { Logical } \\
\text { dissociation }\end{array}$ & $\begin{array}{l}\text { Dividing the problem of digital transformation into components. Determining } \\
\text { the type of logical dissociation - component, alternative, systemic }\end{array}$ \\
\hline Prioritization & $\begin{array}{l}\text { Constructing a hierarchy of parts of the task in accordance with the company's } \\
\text { readiness and the resources available. Determining the mutual influence } \\
\text { among the parts of the task and their combined impact on the current and } \\
\text { future activities of the enterprise. Making decisions on exclusion of some parts } \\
\text { from the general task in accordance with their assessment and defined priority }\end{array}$ \\
\hline $\begin{array}{l}\text { Pilot version of } \\
\text { the } \\
\text { transformation } \\
\text { program }\end{array}$ & $\begin{array}{l}\text { Devising the transformation program is carried out based on the assessment of } \\
\text { parts of the task and the constant adjustment of its provisions in accordance } \\
\text { with the step-by-step results. This allows enhancing sensitivity to unforeseen } \\
\text { events and increasing the efficiency of the chosen direction of transformation }\end{array}$ \\
\hline
\end{tabular}


Continued table 4

\begin{tabular}{|c|l|}
\hline $\begin{array}{c}\text { Priority of } \\
\text { simple } \\
\text { assessment } \\
\text { methods }\end{array}$ & $\begin{array}{l}\text { It is expedient to evaluate the components of the task by simple methods that } \\
\text { simplify the process of obtaining the result, which clearly demonstrates the } \\
\text { correctness of the chosen direction of digital development }\end{array}$ \\
\hline $\begin{array}{c}\text { Information } \\
\text { systematization }\end{array}$ & $\begin{array}{l}\text { Generating the reporting data with an extended context that allows visualizing } \\
\text { the results and submitting them for consideration at all levels of government. } \\
\text { Information systematization is carried out in accordance with the parts of the } \\
\text { task and its integration in general }\end{array}$ \\
\hline $\begin{array}{c}\text { Justification and } \\
\text { control of results }\end{array}$ & $\begin{array}{l}\text { Presenting the general results obtained as a result of performing parts of the } \\
\text { task that is a statement about the process of digital transformation. The } \\
\text { assertion is formed on the basis of real arguments, which are based on the } \\
\text { received information }\end{array}$ \\
\hline
\end{tabular}

For the company, the application of the developed method (see Table 4) is an effective tool for digital transformation, as it involves step-by-step achievement of the set goal with the possibility of timely adjustment of the original plan and minimization of risks.

Companies develop a digital development strategy in accordance with the available resource opportunities and the adoption of a new culture of activity. Thus, it is a transition to a new organizational and methodological level of activity with a change in the mission and values of business.

\section{Conclusions}

Important scientific and practical task to determine the innovative development of modern business, to develop and present a methodological approach to digital transformation is solved in the article with a proposal of an innovative strategy to increase the organizational stability of the company, which determines the development of the business base through designing and implementing a digital transformation project. The main conclusions and results that obtained in the research are as follows:

1. The methodological approach to shaping digital culture at the enterprise, which is an element of a policy of digital innovations developed for the purpose to achieve a new state of activity and prospects of development according to parameters of transforming external business ecosystem, is described. It is substantiated that digital culture is a tool for implementing a systematic approach to building business values, which consists in integrating information management, innovative models, extended competencies and the formulation of a new business philosophy.

2. The key models of digital development have been formed, each of which outlines a set of necessary changes for business and is an element of developing a new value proposition of business that transforms experience in expanding the hypothesis and development strategy, not limited to achieving one goal, but contributing to a multi-objective strategy with their gradual achievement in accordance with the identified priorities for the current time.

3. Innovative strategies for increasing the organizational stability of the company are described with the selection of «critical» components of the strategy, which can be combined in accordance with the priority of the activity for a certain period of time. Such «critical» components are factors of enhancing organizational stability, in the qualitative parameters of which the potential for further transformations is laid, which is expressed in the formulation of the mission, which determines the purpose and meaning of activities, is a guide for development processes.

4. The key aspects of digital business transformation are substantiated with the description of the methodological approach to implementing the program of transformations which is considered as a new business vision, an innovative way and a new philosophy of 
activity which collectively defines business sense in modern conditions. The program of transformations should include innovations, the implementation of which should meet certain values of the company, and therefore be part of the overall mission, which is part of one of the available hypotheses of development.

5. The method of providing digital development is offered, which differs in the possibility of application for projects of different scales and focus on systems thinking and innovation. The proposed method provides an innovative approach to setting and implementing the task of achieving a new state associated with the implementation of digital transformations. This allows the company to move to a new level of organization of activities with the priority of digital technologies that radically change the mission and hypothesis of activities in accordance with key aspects of the external business ecosystem.

\section{Prospects for Further Research}

The proposals and recommendations set out in the scientific article are formed for the development of modern business and are aimed at spreading digital innovations with the transition to a fundamentally new stage of functioning of the business ecosystem. In the future, it is planned to develop the results of the study for devising innovative models of digital business development.

\section{References}

1. How to Go Digital: Practical Wisdom to Help Drive Your Organization's Digital Transformation (2018)

2. C. Linz, G. Müller-Stewens, A. Zimmermann, Radical Business Model

Transformation: Gaining the Competitive Edge in a Disruptive World, Kogan Page (2017)

3. D. Coyle, The Culture Code: The Secrets of Highly Successful Groups, Bantam 304 (2018)

4. A. Stellman, J. Greene, Learning Agile: Understanding Scrum, XP, Lean, and Kanban, (2013)

5. O. Melnychenko, Application of artificial intelligence in the control systems of economic activities, Enterprise economics: modern problems of theory and practice, Materials of the eighth international. scientific-practical conf., September 13-14, 2019, Odessa, Bondarenko M.O. (2019)

6. N. Dalevska, V. Khobta, A. Kwilinski, S. Kravchenko, Entrepreneurship and Sustainability Issues, 6(4), 1839-1860 (2019)

7. A. Geoffrey, Moore Zone to Win: Organizing to Compete in an Age of Disruption (2015)

8. D. L. Rogers, The Digital Transformation Playbook: Rethink Your Business for the Digital Age (Columbia Business School Publishing, NY, 2016)

9. E. Schmidt, J. Cohen, The New Digital Age: Transforming Nations, Businesses, and Our Lives (2013)

10. J. Jr. Thomas, A. Watson, Business and Its Beliefs (McGraw-Hill, NY, 2003)

11. D. Rowan, Non-Bullsh Innovation: How the World's Smartest Leaders Manage Change (Bantam Press, London, 2019)

12. T. Bochulia, A. Kumar Goel, Multidisciplinary Research Journal, XII, 3 (2020) 
13. O. Melnychenko, Journal of Risk and Financial Management, 13(9), 191 (2020)

14. O. Melnychenko, Energies, 14(1), 210 (2021)

15. I. Shkodina, O. Melnychenko, M. Babenko, Financial and Credit Activity: Problems of Theory and Practice, 2(33), 513-521 (2020)

16. U. Vatamanyuk-Zelinska, O. Melnychenko, Problems and Perspectives in Management, 18(3), 11-27 (2020)

17. R. Kostyrko, T. Kosova, L. Kostyrko, L. Zaitseva, O. Melnychenko, Energies, 14, 5080 (2021)

18. O. Melnychenko, Virtual Economics, 2(3), 30-40 (2019)

19. O. Burlaka, A. Kuzior, O. Hanych, S. Kravchenko, O. Melnychenko, Journal of Legal, Ethical and Regulatory Issues, 22(Special Issue 2), 1-5 (2019)

20. S. Cyfert, A. Chwiłkowska-Kubala, W. Szumowski, R. Miśkiewicz, PLoS ONE, 16(4), e0249724 (2021)

21. B. Czyżewski, A. Matuszczak, R. Miskiewicz, Technological and Economic Development of Economy, 25(1), 82-102 (2019)

22. H. Dzwigol, M. Dzwigol-Barosz, R. Miskiewicz, A. Kwilinski, Entrepreneurship and Sustainability Issues, 7(4), 2630-2644 (2020)

23. H. Dzwigol, M. Dzwigol-Barosz, Z. Zhyvko, R. Miskiewicz, H. Pushak, Journal of Security and Sustainability Issues, 8(3), 307-317 (2019)

24. E. Gross-Golacka, M. Kusterka-Jefmanska, R. Miskiewicz, B. Jefmanski, A. Rzepka, T. Kupczyk, European Research Studies Journal, XXIV(2B), 410-429 (2021)

25. R. Miskiewicz, Polityka Energetyczna, 21(2), 49-62 (2018)

26. R. Miskiewicz, Virtual Economics, 2(2), 37-47 (2019)

27. R. Miskiewicz, Marketing and Management of Innovations, 3, 371-381 (2020)

28. R. Miskiewicz, Energies, 13(22), 6106 (2020)

29. R. Miśkiewicz, Journal of Risk and Financial Management, 14(2), 59 (2021)

30. R. Miśkiewicz, R. Wolniak, Sustainability, 12(14), 5776 (2020)

31. K. Pająk, O. Kvilinskyi, O. Fasiecka, R. Miskiewicz, Economics and Environment, 2(61), 122-138, (2017)

32. A. Rzepka, R. Borowiecki, R. Miskiewicz, Z. Olesinski, European Research Studies Journal, XXIV(2), 1149-1162 (2021)

33. P.W. Saługa, K. Szczepańska-Woszczyna, R. Miśkiewicz, M. Chłąd, Energies, 13(18), 4833 (2020)

34. H. Dzwigol, M. Dźwigoł-Barosz, A. Kwilinski, International Journal of Entrepreneurship, 24(1), 1-5 (2020)

35. Y. Kharazishvili, A. Kwilinski, O. Grishnova, H. Dzwigol, Sustainability, 12(21), 8953 (2020)

36. Y. Kharazishvili, A. Kwilinski, O. Sukhodolia, H. Dzwigol, D. Bobro, J. Kotowicz, Energies, 14(8), 2126 (2021)

37. Y. Kharazishvili, A. Kwilinski, H. Dzwigol, V. Liashenko, Virtual Economics, 4(2), 740 (2021)

38. A. Kwilinski, O. Vyshnevskyi, H. Dzwigol, Journal of Risk and Financial Management, 13(7), 142 (2020) 
39. O. Lyulyov, T. Pimonenko, A. Kwilinski, H. Dzwigol, M. Dzwigol-Barosz, V. Pavlyk, P. Barosz, Energies, 14(2), 373 (2021)

40. O. Lyulyov, I. Vakulenko, T. Pimonenko, A. Kwilinski, H. Dzwigol, M. DzwigolBarosz, Energies, 14(12), 3497 (2021)

41. A. Kwilinski, H. Dzwigol, V. Dementyev, International Journal of Entrepreneurship, 24(1 Special Issue), 1-5 (2020)

42. O. Arefieva, O. Polous, S. Arefiev, V. Tytykalo, A. Kwilinski, IOP Conference Series: Earth and Environmental Science, 628, 012039 (2021)

43. V. Boiko, A. Kwilinski, M. Misiuk, L. Boiko, Economic Annals-XXI, 175(1-2), 68-72 (2019)

44. S. Bogachov, A. Kwilinski, B. Miethlich, V. Bartosova, A. Gurnak, Entrepreneurship and Sustainability Issues, 8(2), 487-499 (2020)

45. O. Chygryn, Y. Bilan, A. Kwilinski, Marketing and Management of Innovations, 3, 356-368 (2020)

46. V.V. Dementyev, A. Kwilinski, Journal of Institutional Studies, 12(1), 100-116 (2020)

47. V. Koibichuk, N. Ostrovska, F. Kashiyeva, A. Kwilinski, Marketing and Management of Innovations, 1, 253-265 (2021)

48. V. Kondratenko, O. Okopnyk, L. Ziganto, A. Kwilinski, Marketing and Management of Innovations, 1, 87-94 (2020)

49. A. Kuzior, A. Kwilinski, V. Tkachenko, V. Entrepreneurship and Sustainability, 7(2), 1353-1376 (2019)

50. A. Kuzior, A. Kwilinski, I. Hroznyi, Energies, 14(9), 2572 (2021)

51. A. Kuzior, O. Lyulyov, T. Pimonenko, A. Kwilinski, D. Krawczyk, Sustainability, 13(15), 8145 (2021)

52. A. Kwilinski, Virtual Economics, 1(1), 7-25 (2018)

53. A. Kwilinski, Marketing and Management of Innovations, 4, 116-128 (2018)

54. A. Kwilinski, Academy of Accounting and Financial Studies Journal, 23(SI2), 1-6 (2019)

55. A. Kwilinski, V. Tkachenko, A. Kuzior, Journal of Security and Sustainability Issues, 9(2), 561-570 (2019)

56. A. Kwilinski, N. Dalevska, S. Kravchenko, I. Hroznyi, I. Kovalenko, Journal of Entrepreneurship Education, 22(SI1), 1-7 (2019)

57. A. Kwilinski, I. Ruzhytskyi, V. Patlachuk, O. Patlachuk, B. Kaminska, Journal of Legal, Ethical and Regulatory Issues, 22(SI2), 1-6 (2019)

58. A. Kwilinski, R. Volynets, I. Berdnik, M. Holovko, P. Berzin, P. Journal of Legal, Ethical and Regulatory Issues, 22(SI2), 1-6 (2019)

59. A. Kwilinski, K. Pajak, O. Halachenko, S. Vasylchak, Y. Pushak, P. Kuzior, Marketing and Management of Innovations, 4, 172-181 (2019)

60. A. Kwilinski, A. Kuzior, Management Systems in Production Engineering, 28(2), 119$123(2020)$

61. A. Kwilinski, Y. Zaloznova, N. Trushkina, N. Rynkevych, E3S Web of Conferences, 168, $00031(2020)$

62. A. Kwilinski, M. Dielini, O. Mazuryk, V. Filippov, V. Kitseliuk, Journal of Security and Sustainability Issues, 10(1), 345-358 (2020) 
63. A. Kwilinski, D. Shteingauz, V. Maslov, Financial and Credit Activities: Problems of Theory and Practice, 3(34), 133-140 (2020)

64. A. Kwilinski, I. Slatvitskaya, T. Dugar, L. Khodakivska, B. Derevyanko, International Journal of Entrepreneurship, 24(1 Special Issue), 1-8 (2020)

65. A. Kwilinski, V. Litvin, E. Kamchatova, J. Polusmiak, D. Mironova, International Journal of Entrepreneurship, 25(1), 1-8 (2021)

66. Y. Kyrylov, V. Hranovska, V. Boiko, A. Kwilinski, L. Boiko, L. Journal of Risk and Financial Management, 13(12), 303 (2020)

67. V. Lakhno, V. Malyukov, T. Bochulia, Z. Hipters, A. Kwilinski, O. Tomashevska, International Journal of Civil Engineering and Technology, 9(8), 1802-1812 (2018)

68. O. Lyulyov, T. Pimonenko, A. Kwilinski, Y. Us, E3S Web of Conferences, 250, 03006 (2021)

69. K. Pająk, B. Kamińska, O. Kvilinskyi, O. Financial and Credit Activity: Problems of Theory and Practice, 2(21), 204-217 (2016)

70. T. Savchenko, N. Basiurkina, O. Rodina, A. Kwilinski, Management Theory and Studies for Rural Business and Infrastructure Development, 41(1), 43-61 (2019)

71. V. Tkachenko, A. Kwilinski, O. Korystin, N. Svyrydiuk, I. Tkachenko, Journal of Security and Sustainability, 8(3), 375-385 (2019)

72. V. Tkachenko, A. Kwilinski, M. Klymchuk, I. Tkachenko, Management Systems in Production Engineering, 27(2), 119-123 (2019)

73. V. Tkachenko, A. Kwilinski, I. Tkachenko, P. Puzyrova, Marketing and Management of Innovations, 2, 228-238 (2019)

74. V. Tkachenko, A. Kwilinski, B. Kaminska, I. Tkachenko, P. Puzyrova, Financial and Credit Activity: Problems of Theory and Practice, 3(30), 85-94 (2019)

75. V. Tkachenko, A. Kuzior, A. Kwilinski, Journal of Entrepreneurship Education, 22(6), 1-10 (2019)

76. L. Karpenko, M. Serbov, A. Kwilinski, V. Makedon, S. Drobyazko, Academy of Strategic Management Journal, 17(5), 1-7 (2018)

77. J. Polcyn, Sustainability, 13(15), 6846 (2021)

78. R. Abazov, Herald of Journalism, 58(4), 34-43 (2021) 